\title{
1. A Study on D0 Run2b Stave Structural Performance
}

\author{
Giobatta Lanfranco \\ Fermi National Accelerator Laboratory \\ Particle Physics Division / Silicon Engineering Group - Mechanical Dep. \\ e-mail: giobatta@fnal.gov
}

30 April 2002

\section{Abstract}

Two different structural solutions have been proposed and studied for the D0 Run2b stave (Figure 1 and Figure 3). The way the stave structural stiffness is achieved in both designs is essentially the same: the structural material is displaced as far as possible from the neutral axis in order to increase the bending moment of the stave.

The agreement of the measured data with what has been theoretically predicted is excellent. The $\mathrm{C}$ channel stave with dog-bones glued on top of the sensor (stave \#2) has outperformed the other mockups with a predicted sag of $51 \mu \mathrm{m}$ for a distributed load of $2.28 \mathrm{~N} / \mathrm{m}$ [0.013 lbf/in] and a consequent natural frequency of $89.2 \mathrm{~Hz}$. The other three $\mathrm{C}$ channel staves with the dog-bones not glued on the sensor have a bending stiffness that is $-19.0 \%,-10.8 \%,+4.0 \%$ of that of stave \#2, being $11.0 \%$, $7.8 \%, 15.1 \%$ lighter respectively.

An optimized stave structural proposal with $130.5 \%$ of the design stiffness within the mass budget is presented at the end of this paper.

\section{The two stave layouts}

The first stave design (Figure 1) is obtained enclosing the entire stave core between two carbon fiber shells presenting $20.2 \mathrm{~mm} \times 6.2 \mathrm{~mm}$ cut-outs to allow the cables to be plugged in the hybrid connectors. The initial advantage that this solution seems to offer in terms of wirebonds protection is penalized by the significant local deformations that the thin shells are subject to when an external load is applied ${ }^{1}$.

\footnotetext{
${ }^{1}$ In Figure 2 it is possible to see the finite element study on the effects of a concentrated 100 grams load on the shell local deformation.
} 
Besides, the part of shell that effectively takes part in the structural stiffness is reduced by the width of the holes, and this consequently translates in a waste of material. This approach has also the disadvantage that the shear stresses between the upper and bottom flanges are carried through a weak web (because of the glue seam between the two shells) and it is not clear how the assembly process can be easily achieved. However, with this design the shells are glued on the core with a top-down movement, making the installation less critical for the wirebonds integrity. Two of the existing mockups follow this design and in Figure 7 and Figure 11 the deflection test results are shown.

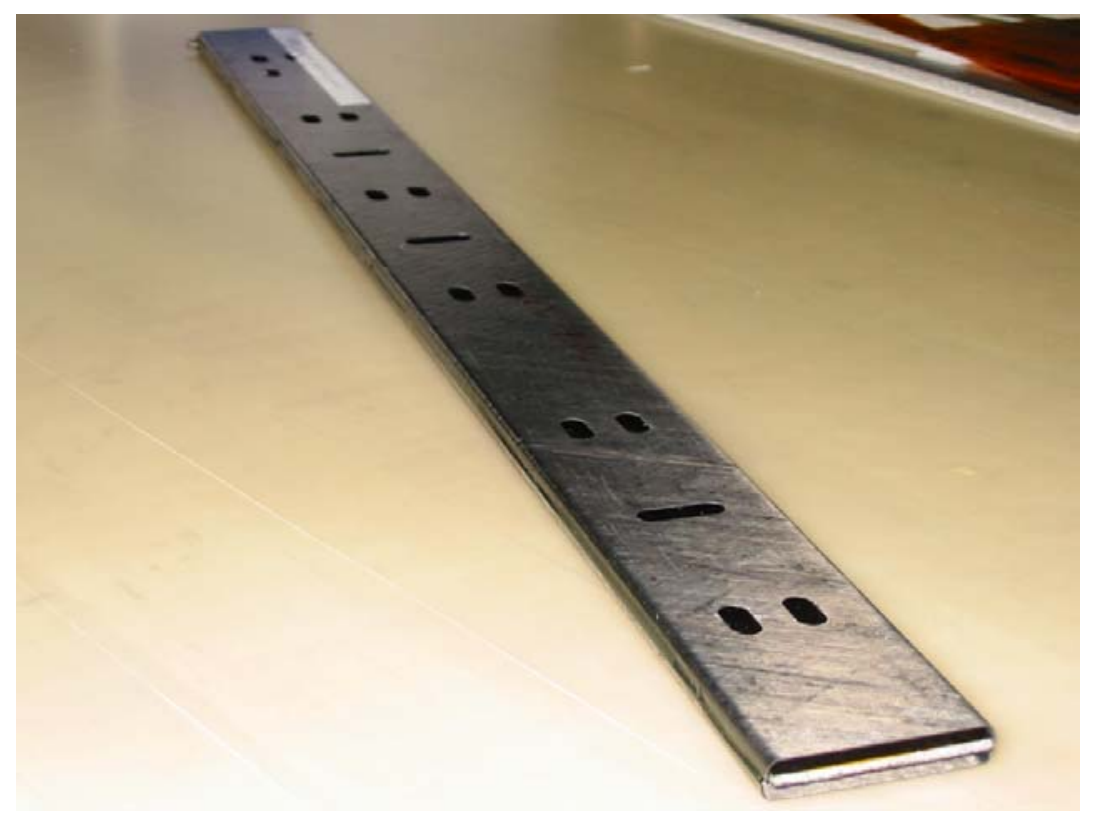

Figure 1 - The stave mockup with outer shell solution. Stave \#4. 


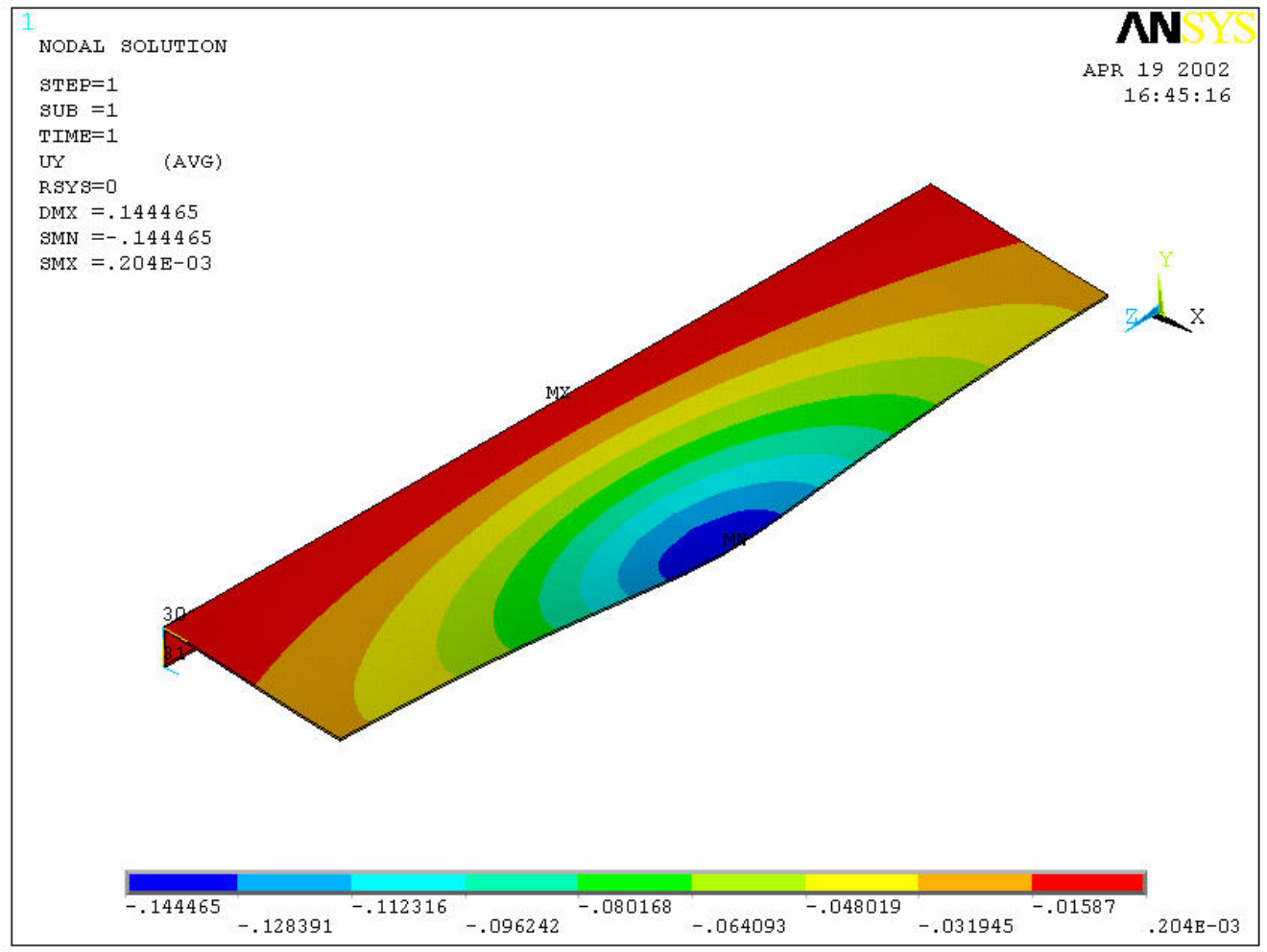

Figure 2 - Effects of a 100gr concentrated mass located at the center of a10cm long shell structure. Units: [mm]. Given the symmetry, only a quarter of the structure is modeled. The web is fixed along the neutral plane and the $250 \mu m$ shell lay-up is made according to that reported in $\$ 5$.

The second stave design (Figure 3) has two composite $\mathrm{C}$ shape longitudinal channels glued to the stave core and interconnected by 24 carbon fiber dog-bones (the name coming from their initial shape). The function of the dog-bones is to provide protection to the sensors and the wirebonds from the cabling and to offer the structure a moderate torsional stiffness. This design seems to solve most of the problems affecting the shell solution but it requires a higher level of precision during the channel assembly $^{2}$. The dog-bones may be simple $250 \mu \mathrm{m}$ carbon fiber skins glued on the internal side of the C channel flanges or wafers of kapton, Rohacell and carbon fiber ${ }^{3}$ glued on top of the silicon. The former solution has the advantage to add very little mass to the structure and to avoid any contact with the sensor. The latter has the benefit to contribute in carrying the stress directly into the supporting structure - offering so a stiffer design - and to protect the hybrids during the channel installation. In

\footnotetext{
${ }^{2}$ Because of the way the channels are installed, with a lateral movement, controlling the inner distance between the flanges is critical in order to avoid hitting the wirebonds. Although with a preliminary mold, the channels produced in an autoclave are very good (the repeatability of the flange inner height is within 1 mil).

${ }^{3}$ The kapton skin being the part of dog-bone in direct contact with the sensor.
} 
Figure 3 it is possible to see an enlarged view of a stave with Kevlar skin core and the alignment pins at $\mathrm{z}=610 \mathrm{~mm}$.
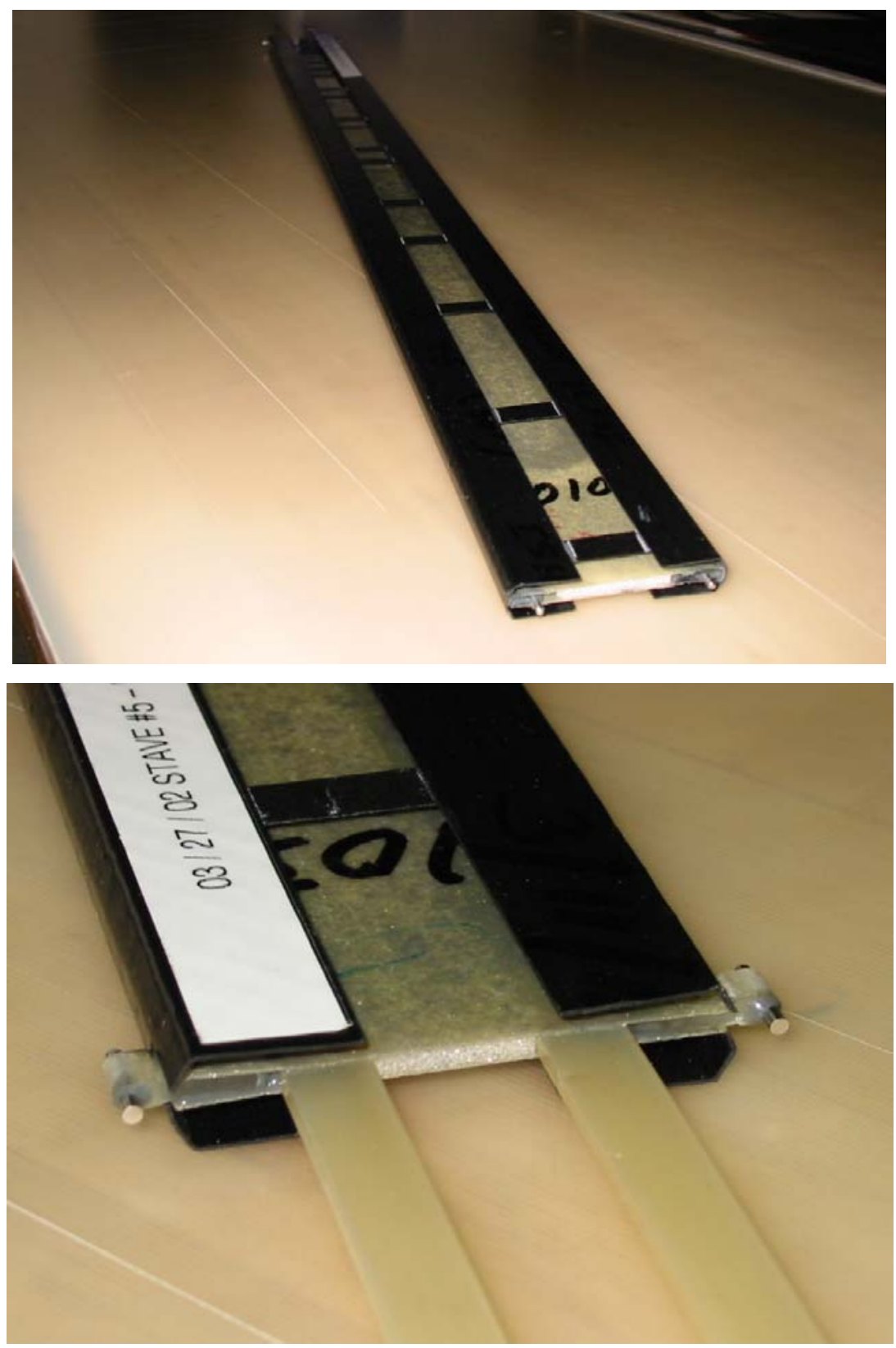

Figure 3-The stave mockup with C channels configuration and close-up of the alignment pins region at $z=610 \mathrm{~mm}$. The rectangular shaped PEEK cooling line is also visible. Stave \#5.

The $\mathrm{C}$ channel section (Figure 4) has been optimized to provide the best compromise between bending stiffness and compact profile ${ }^{4}$.

\footnotetext{
${ }^{4}$ to reduce the insertion cut-out in the bulkhead at $\mathrm{z}=610 \mathrm{~mm}$.
} 


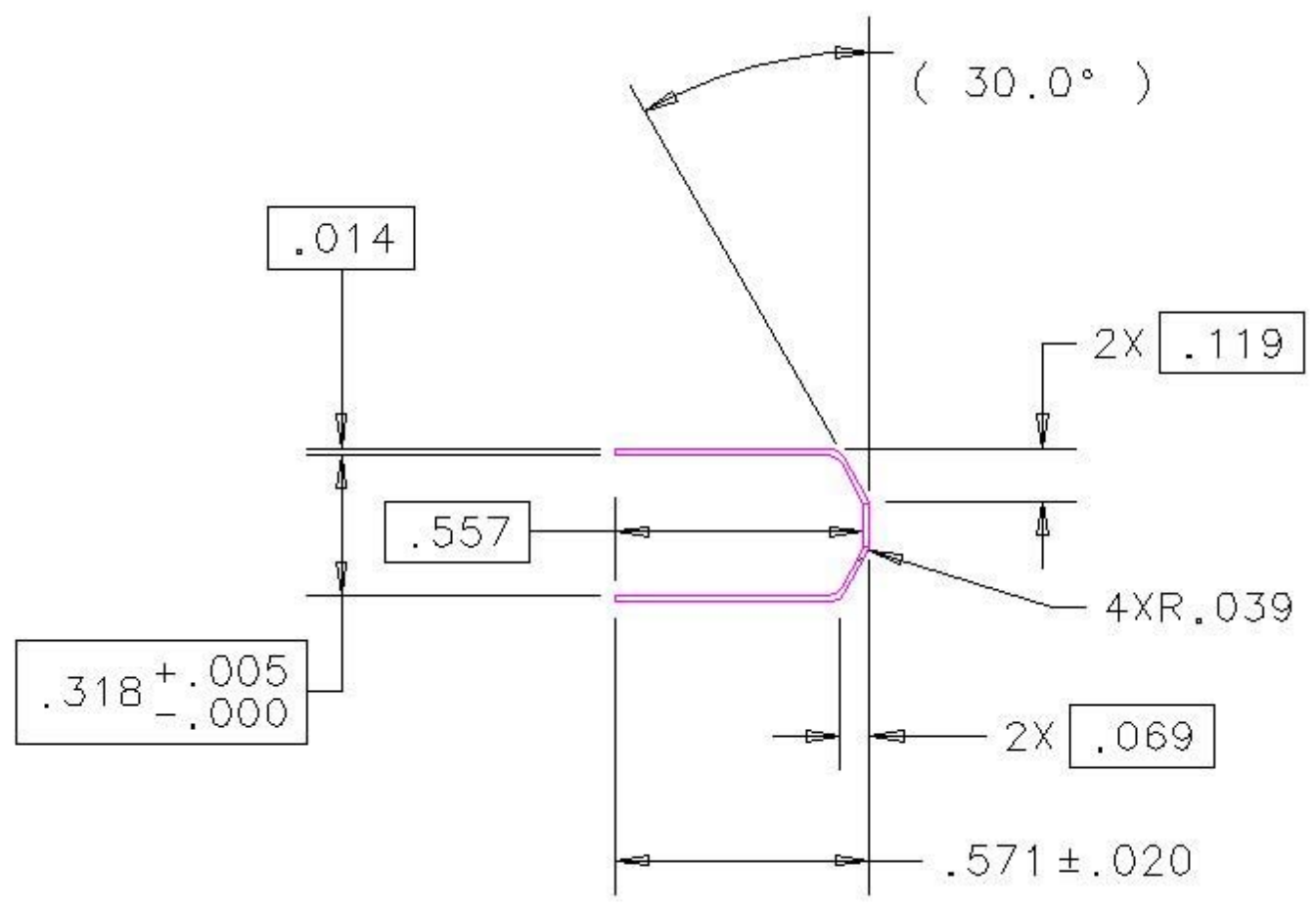

Figure 4-Optimized C channel profile.

Figure 5 illustrates a kapton skin core before the $\mathrm{C}$ channels are glued along the sides. 

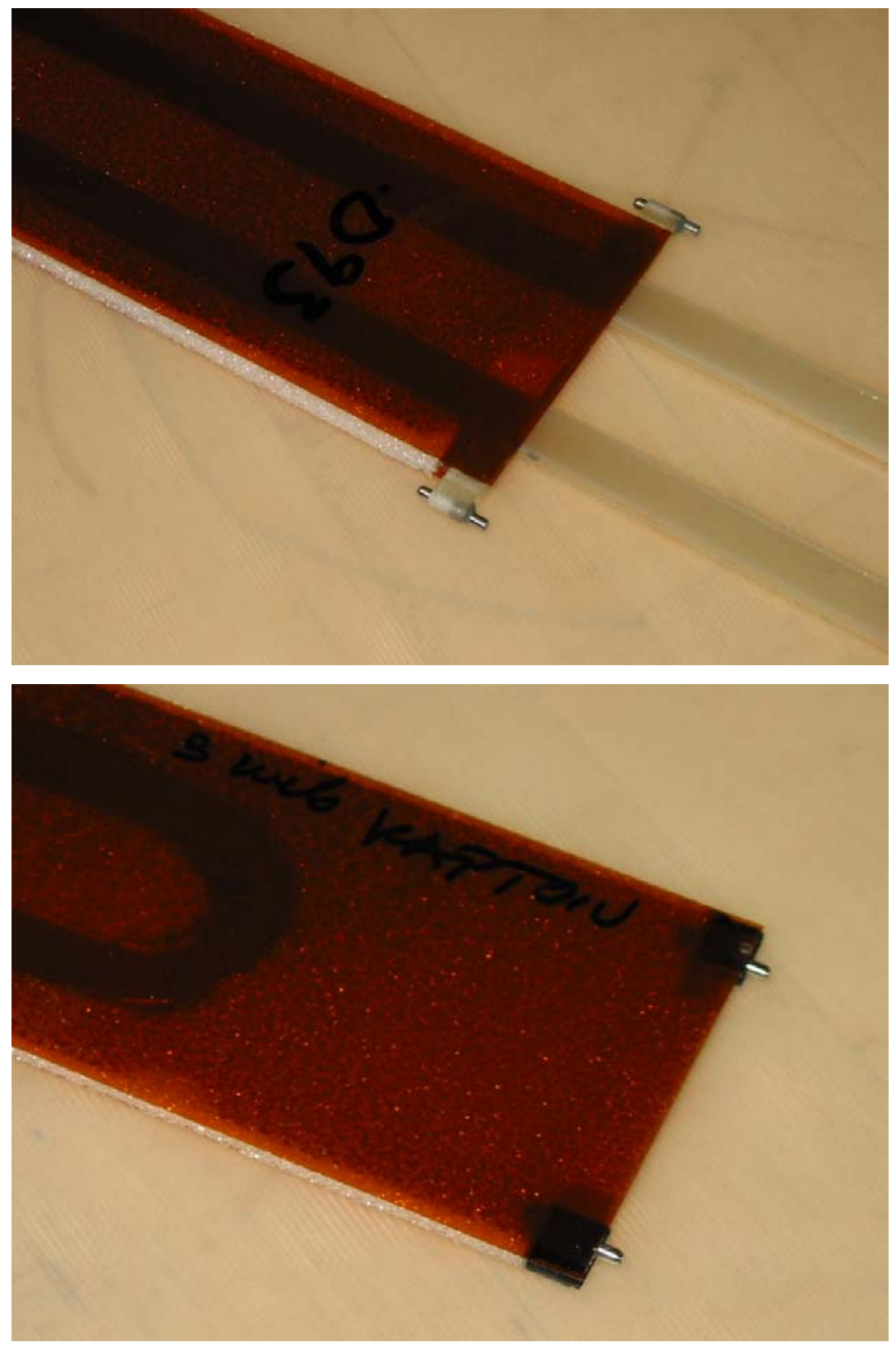

Figure 5 - Core detail with kapton skin and alignment pins. Top: $z=609.6 \mathrm{~mm}$ end; bottom: $z=0 \mathrm{~mm}$ end.

Figure 8 through Figure 13 show the results of deflection test of this stave design. For the current tests no silicon sensors have been glued on top of the cores.

\section{Test description}

The estimated distributed load that is supposed to be carried by the stave is about $2.28 \mathrm{~N} / \mathrm{m}(0.013$ lb/in), and it is due to the weight of the silicon sensors, the hybrids, the cabling, the coolant and the supporting structure itself. In these conditions the stave maximum allowed vertical displacement is 
$60 \mu \mathrm{m}$ which yields a target bending stiffness of $68.228 \mathrm{~Pa}_{\mathrm{m}}{ }^{4}$ from which it is possible to draw the design goal line of Figure 7 through Figure 13 (dashed blue line).

The test has been performed placing the stave on two end supports and loading the center of the stave while a dial indicator was registering the deflection (Figure 6). The dial indicator stylus was positioned on one of the two upper flanges for the channel design, given their intrinsic local rigidity; for the shell design, the stylus was placed on a pin glued on the core (stave $\# 0$ ), to directly measure the core deflection, or on the lower and on the upper shell (stave \#4), to compare the effect of the local deformation.

The load test has been repeated with the stave flipped to load it in the opposite direction in order to compare possible deflection discrepancy. No differences have been noticed except for stave \#4 (Figure 11), but this can be explained by the fact that the two shells were not perfectly matching at their interface.

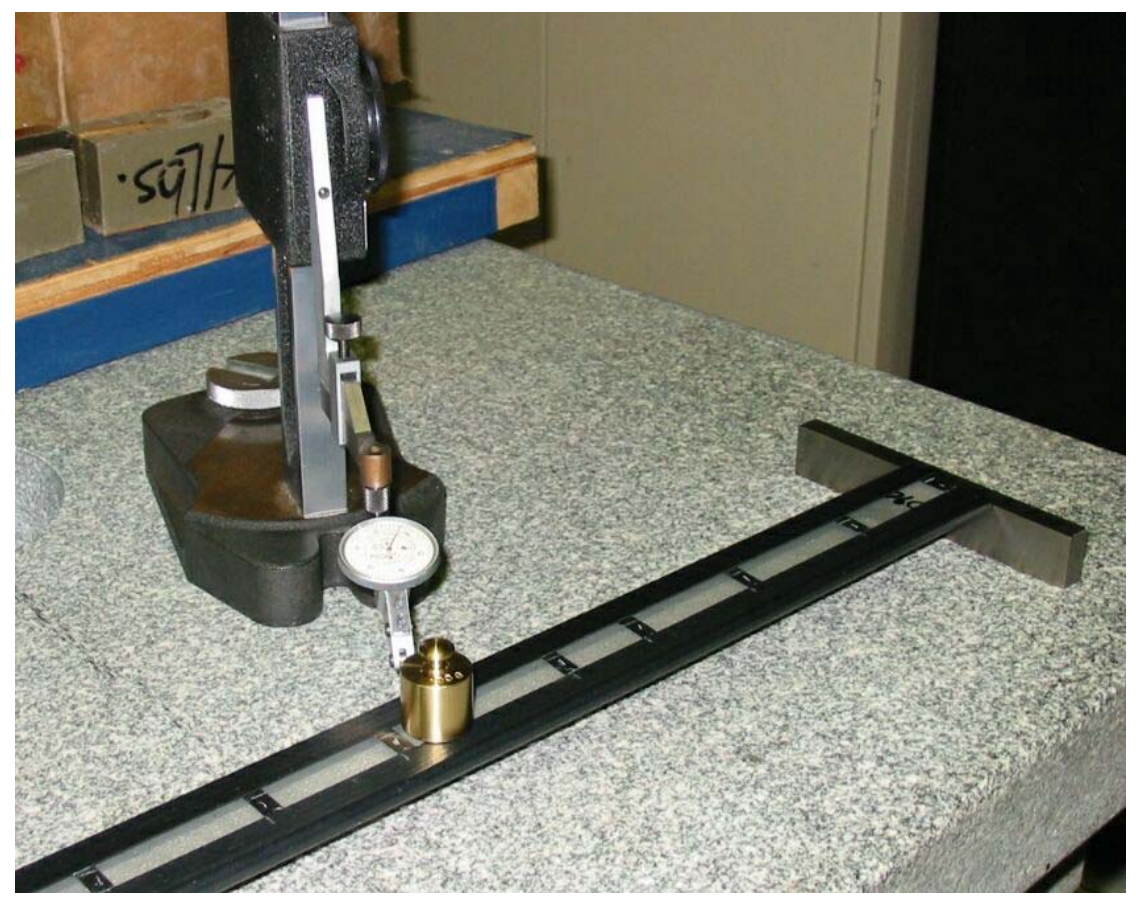

Figure 6 - Setup of the deflection test.

\section{Results}

The agreement of the measured data with theoretical prediction is excellent. Except stave \#1 (Figure 8) because of the aluminum sheet in the lay-up, all the mockups based on the channel configuration 
performed within or close to the design specifications. The dog-bones glued on top of the sensors offer a slight increase in bending stiffness at the cost of about 7 grams of extra mass ${ }^{5}$.

In staves \#2 and \#3 the first and last longitudinal plies of the lay-up have been applied only along the flanges and not along the web (to highlight this in the following graphs a * designates the partial ply); although there is a modest gain in mass ( $\sim 2$ grams), the additional lay-up labour ${ }^{6}$ does not justify this solution.

The design differences between the six stave mockups, together with their overall mass, the predicted sag under the estimated distributed load of $0.013 \mathrm{lb} / \mathrm{in}$ and the stave bending stiffness have been summarized in Table 2.

The formula

$$
f=\frac{1.2769}{2 \pi} \sqrt{\frac{g}{\delta_{\max }}}
$$

Equation 1

where $g$ is the gravitational acceleration and $\delta_{\max }$ the maximum sag, represents a simple but close approximation for the fundamental frequency of a uniform thin plate of ordinary shape having any combination of fixed, partially fixed or simply supported boundaries (Ref. 1). Having imposed that the sag does not exceed $60 \mu \mathrm{m}$ implies that the natural frequency of the stave will never be lower than about $80 \mathrm{~Hz}$, reducing then the danger of $60 \mathrm{~Hz}$ resonance. In Table 2 the natural frequency of the tested mockup staves is given, based on the expected sag due to the estimated overall stave mass ( 140gr).

Finally, a pronounced creep has been observed in stave \#1 (channel design) and in staves \#0 and \#4 (the two shell mockups). About the former stave, this could be explained by the presence of the aluminum in the lay-up, the only substantial difference with the other models based on the same design.

\footnotetext{
${ }^{5}$ The estimated total stave mass is $144.75 \mathrm{gr}, 45.8 \mathrm{gr}$ of which is the predicted mass of the structure. At the present time, stave \#6 is the lightest structure built (61.81gr) but it is still $16 \mathrm{gr}$ beyond what is expected, pointing out the necessity to improve the control of the glue thickness.

${ }^{6}$ During the lay-up procedure, the first two longitudinal prepreg strips are directly applied on the mold; then the first set of $\left[ \pm 60^{\circ} / 0^{\circ}\right]$ plies, previously stacked up together and containing the only complete longitudinal ply, are wrapped around the mold; then the next $\left[ \pm 60^{\circ}\right]$, previously stacked too. After partial curing, the final two longitudinal prepreg strips are applied and the channel undergoes a final curing step. This extra step is determined by the difficulty to precisely place the two strips in case they were stacked on the last $\left[ \pm 60^{\circ}\right]$ set before being wrapped around the mold.
} 
The creep in the shell staves, as already pointed out, could be due to the fact that the shear stresses along the web are carried through the weak epoxy seam keeping the shells together.

\section{Stave \#0 (Shell) Deflection - $\left[0^{\circ} / 0^{\circ} / 90^{\circ} / 0^{\circ} / 0^{\circ}\right]$ stave weight $=72.42 \mathrm{gr} /$ glue: $\mathrm{DP}-190$}

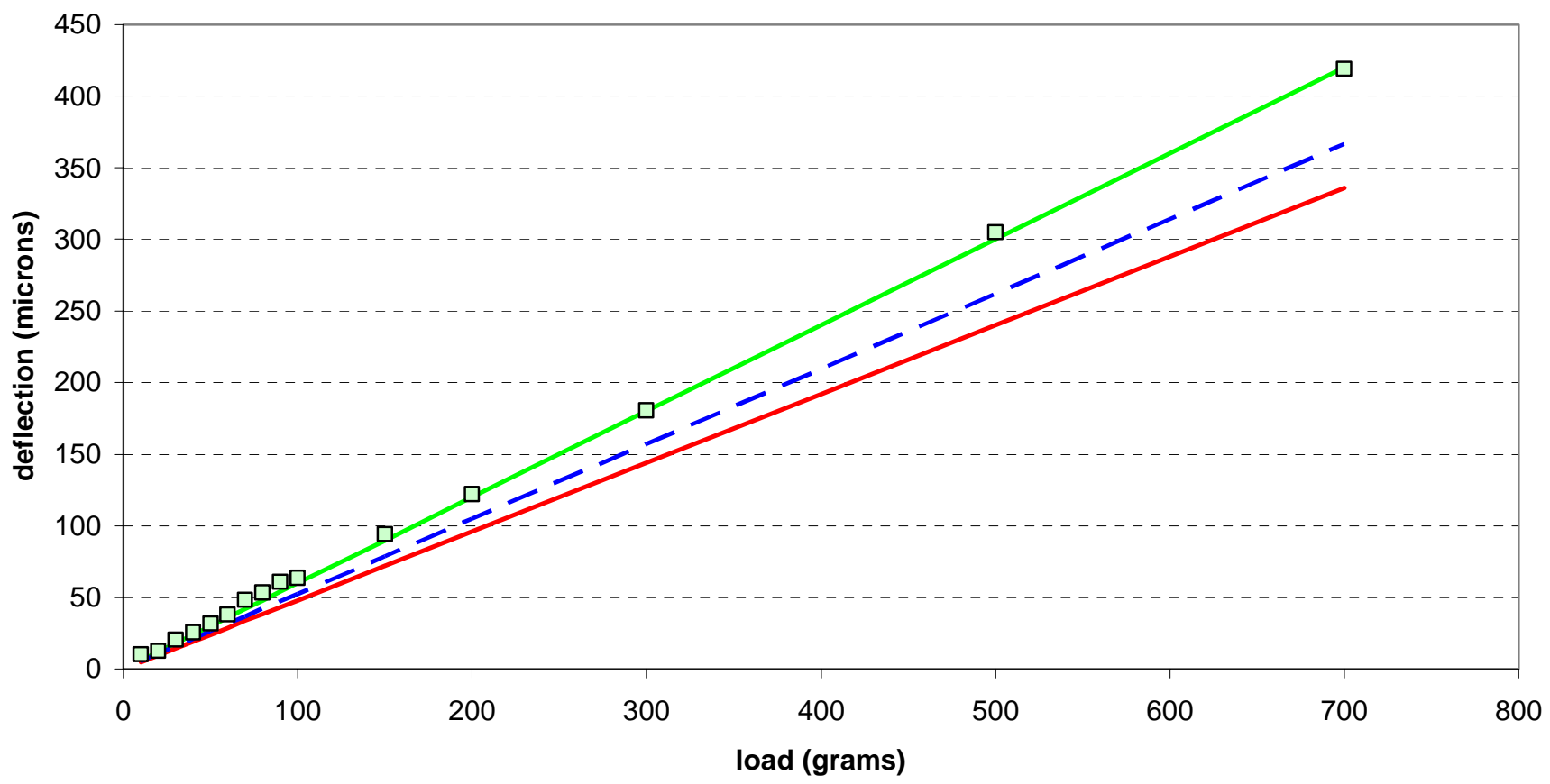

$\square \quad$ Shell \#0 $\longrightarrow$ Shell pred. With shear lag —Shell pred. with DeSaint Venant $—-$ Design Goal

Figure 7 - Stave \#0 mockup deflection study. The shell structural elements are made of carbon fiber prepreg (Mitsubishi $\left.\mathrm{K139},\left[0^{\circ}, 0^{\circ}, 90^{\circ}, 0^{\circ}, 0^{\circ}\right]\right)$. The core is made of Rohacell, $200 \mu \mathrm{m}$ thick carbon skin and 50 $\mu \mathrm{m}$ thick Kapton. This model is about 0.5 inch shorter than the final design goal and $1.2 \mathrm{~mm}$ taller (overall stave height: $10.00 \mathrm{~mm}$ ). The shear lag theory correctly predicts the behavior of this thin wall structure while the De Saint Venant theory fails. The design goal line has been opportunely adjusted by a $(8.8 / 10)^{2}$ scale factor to account for the extra height of this stave. 
Stave \#1 Deflection - $\left[0^{\circ} / \pm^{\circ} 45 /\right.$ Al foil $\left./ \pm 45^{\circ} / 0^{\circ}\right]$

$15 \mathrm{~mm}$ dogbones glued on top of sensor - stave weight $=77.60 \mathrm{gr} /$ glue: DP-190

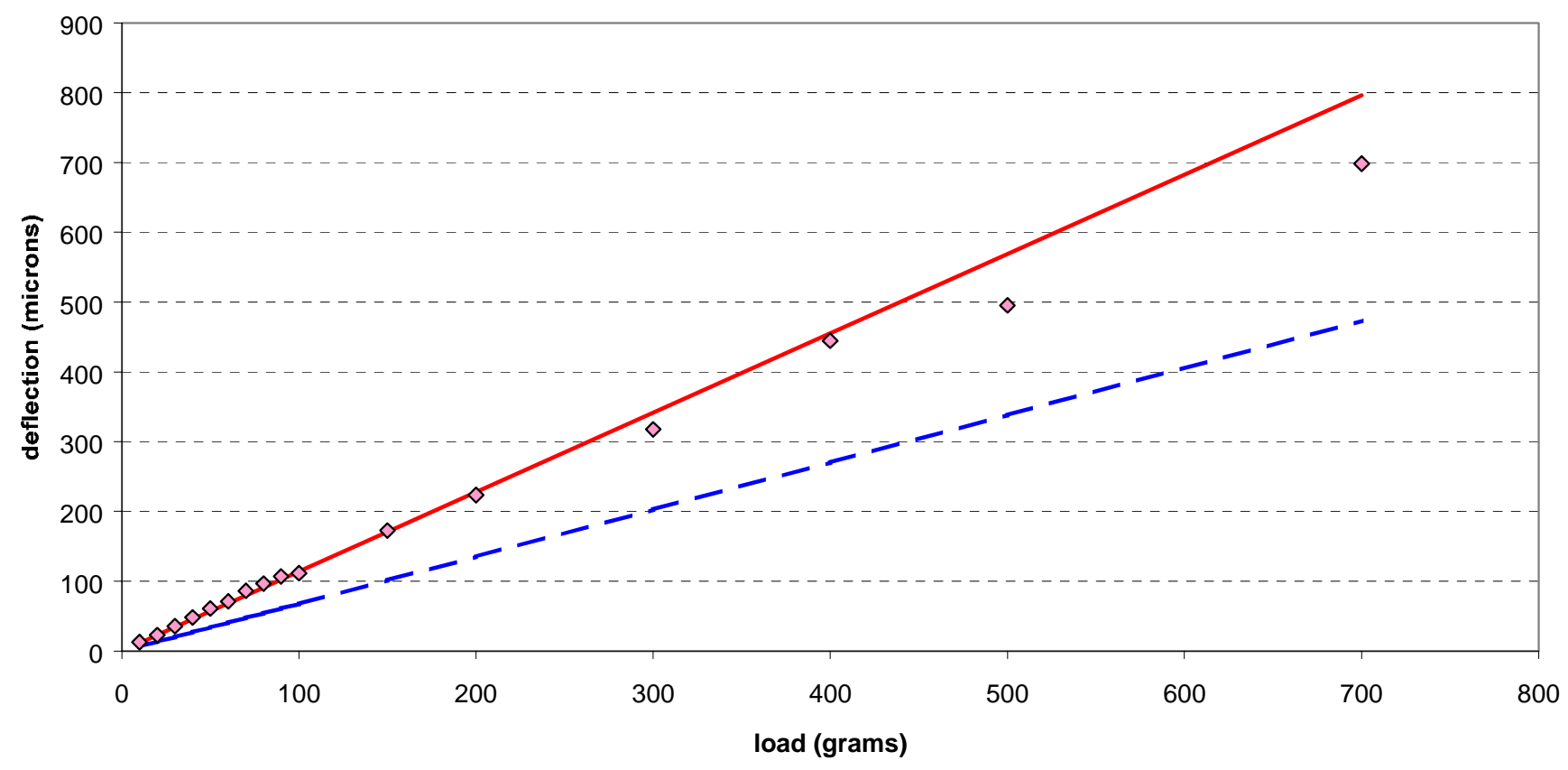

$\diamond \quad$ C CHANNEL \#1 - theor. prediction $[0 \pm 45 \mathrm{Al} \pm 450]$ - Design Goal

Figure 8 - Stave \#1 mockup deflection study. The $15 \mathrm{~mm}$ wide dog-bones (wirebonds protections) are glued on top of the silicon sensors. The $C$ channel structural elements are $\sim 13.2 \mathrm{~mm}$ wide $\times \sim 9.0 \mathrm{~mm}$ tall and made of carbon fiber prepreg (Mitsubishi K139, $\left[0^{\circ}, \pm 45^{\circ}\right]$ lay-up) with interposed a 1 mil aluminum sheet. The core is made of Rohacell, $200 \mu \mathrm{m}$ thick carbon skin and $50 \mu \mathrm{m}$ thick Kapton. 
Stave \#2 Deflection - $\left[0^{\circ *} / \pm^{\circ} 60 / 0^{\circ} / \pm 60^{\circ} / 0^{\circ}\right.$ *]

$7.5 \mathrm{~mm}$ dogbones glued on top of sensor - stave weight $=72.79 \mathrm{gr} /$ glue: DP-190

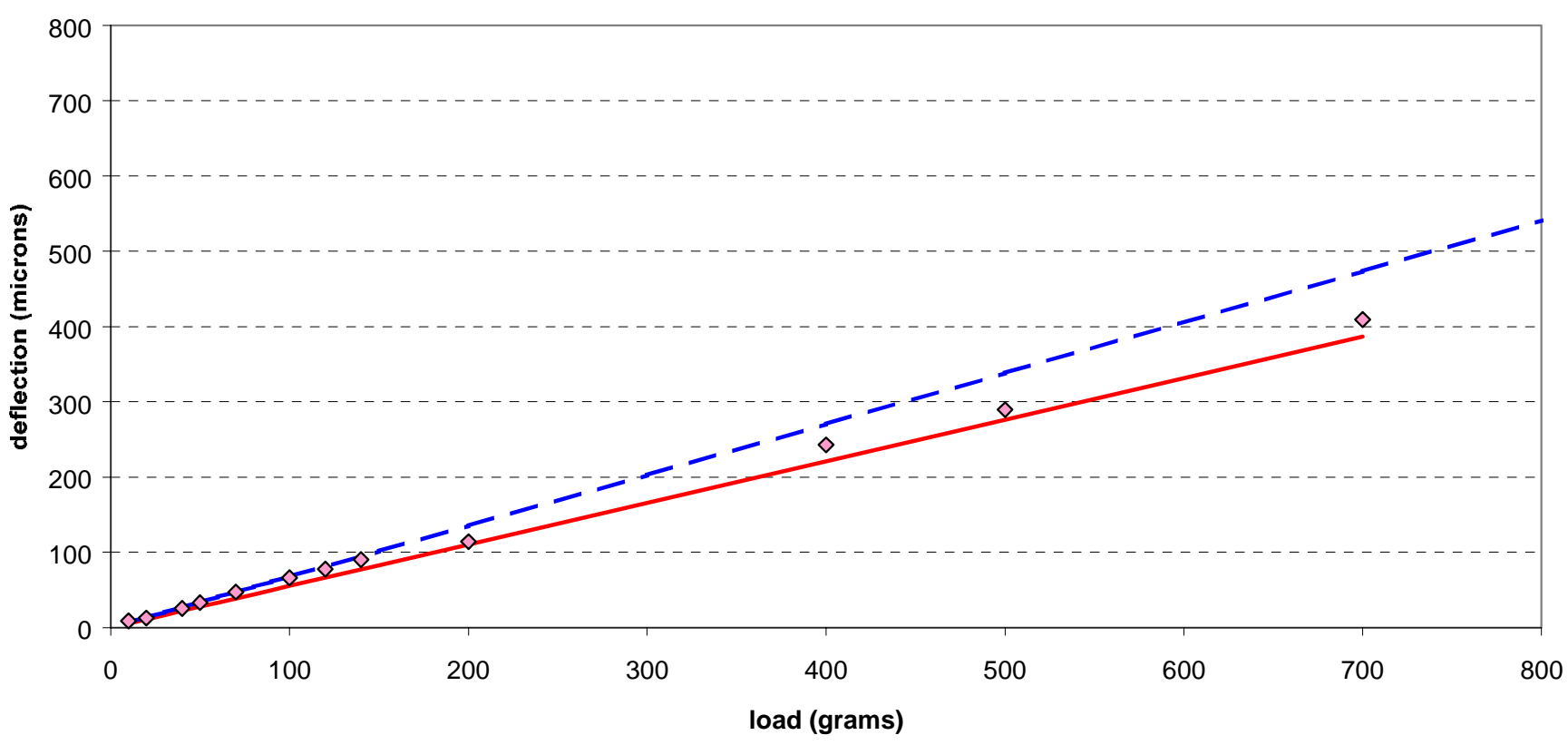

$\diamond \quad$ C CHANNEL \# 2 - theor. prediction $[0 \pm 600 \pm 600]$ - Design Goal

Figure 9 - Stave \#2 mockup deflection study. The dog-bones are still glued on top of the silicon sensor but now their width has been reduced to $7.5 \mathrm{~mm}$. The C channel width has been increased to $\sim 15.7 \mathrm{~mm} \times 9.2 \mathrm{~mm}$ tall and the carbon fiber (Mitsubishi K139) 7 plies lay-up is now $\left[0^{\circ}, \pm 60\right]$ (the aluminum sheet has been replaced with a longitudinal lamina and the outer longitudinal plies are only on the flanges). The core is made of Rohacell, $200 \mu \mathrm{m}$ thick carbon skin and 50 $\mu \mathrm{m}$ thick kapton. 
Stave \#3 Deflection - $\left[0^{\circ *} / \pm^{\circ} 60 / 0^{\circ} / \pm 60^{\circ} / 0^{\circ *}\right]$

dogbones glued on flanges only - stave weight $=64.77 \mathrm{gr} /$ glue: DP-190

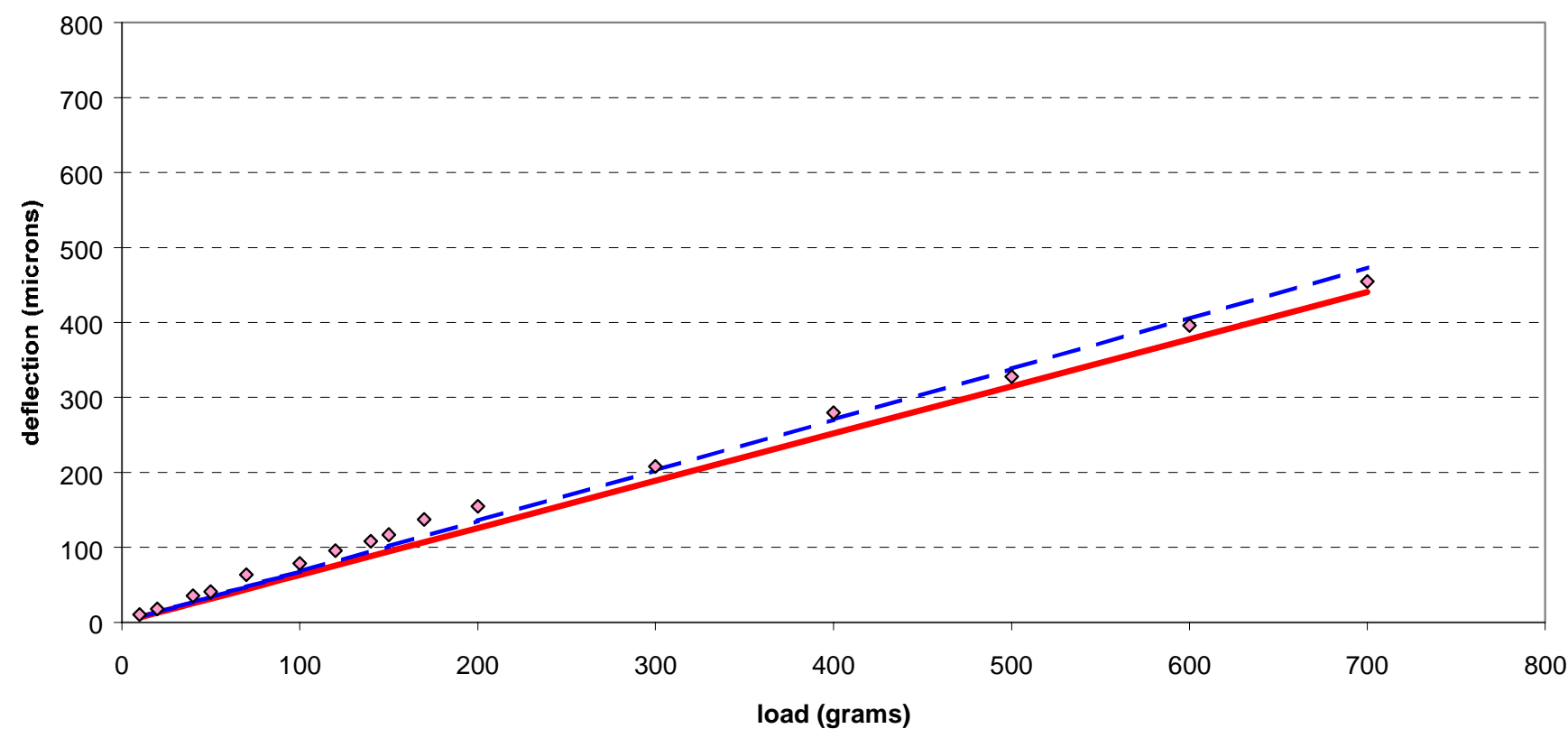

$\diamond \quad$ C CHANNEL \# 3 theor. prediction $[0 \pm 600 \pm 600]$ - Design Goal

Figure 10 - Stave \#3 mockup deflection study. The dog-bones are reduced to carbon sheets $(7.5 \mathrm{~mm}$ wide $\times 200 \mu \mathrm{m}$ thick). The $C$ channels are analogous to that of the stave \#2 (Mitsubishi K139 $\left[0^{\circ}, \pm 60,0^{\circ}, \pm 60^{\circ}, 0^{\circ}\right.$ ] lay-up, outer longitudinal plies only on the flanges, overall height $9.20 \mathrm{~mm}$ ). The core is made of Rohacell, $200 \mu \mathrm{m}$ thick carbon skin and 50 $\mu \mathrm{m}$ thick Kapton. 


\section{Stave \# 4 (Shell) Deflection - $\left[0^{\circ} /-^{\circ} 60 /+^{\circ} 60 /+{ }^{\circ} 60 /-60^{\circ} / 0^{\circ}\right]$ stave weight $=65.86 \mathrm{gr} /$ glue: $\mathrm{DP}-190$}

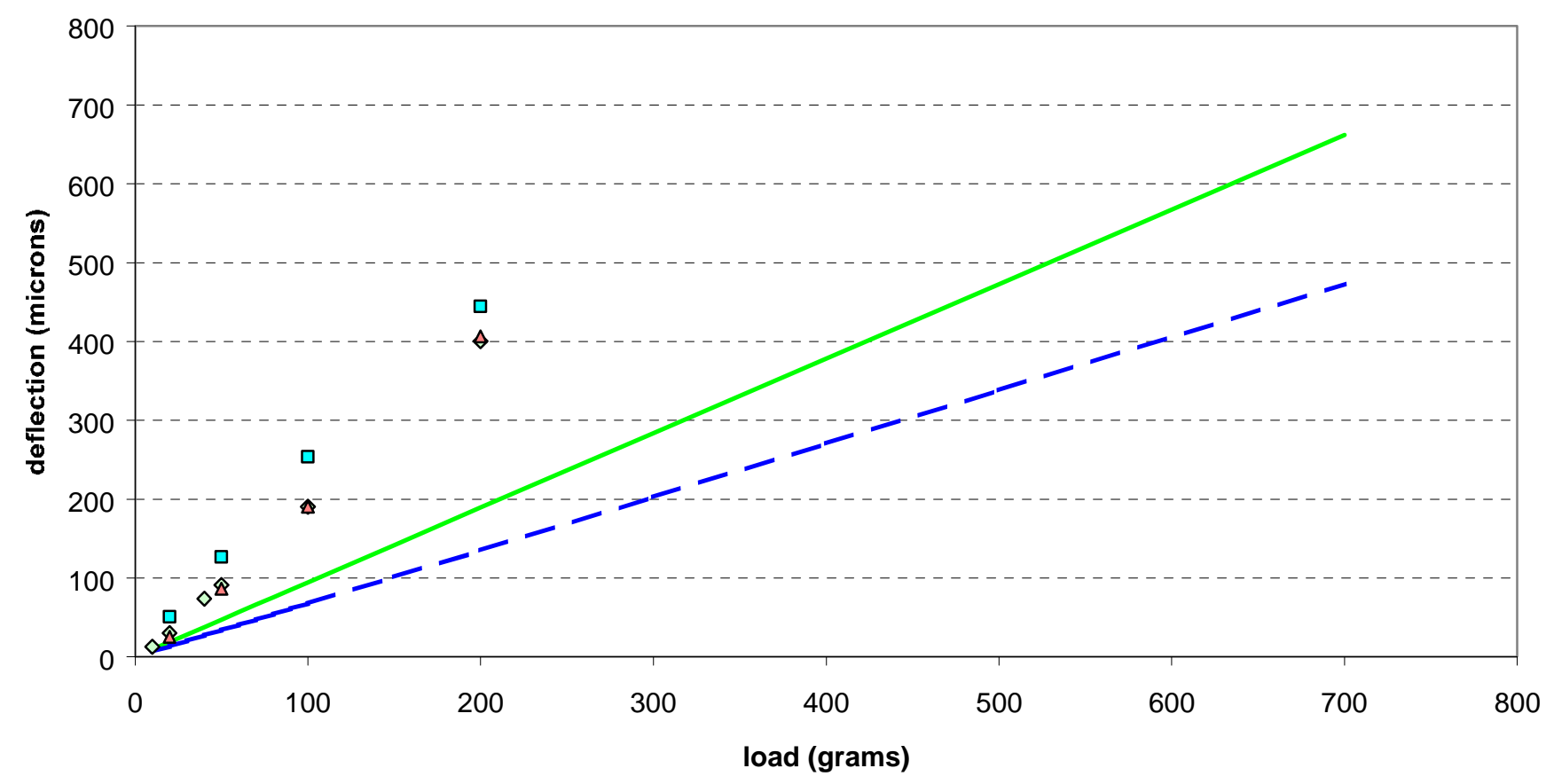

\begin{tabular}{|c|c|c|c|c|c|}
\hline$\diamond$ & stylus on bottom shell & $\square$ & Stylus on top - Stave Side 1 & $\Delta$ & Stylus on top - Stave Side 2 \\
\hline & theor. prediction $[0 \pm 60$ & & Design Goal & & \\
\hline
\end{tabular}

Figure 11 - Stave \#4 mockup deflection study. The shell structural elements are made of carbon fiber prepreg (Mitsubishi K139, 6 plies $\left[0^{\circ}, \pm 60, \pm 60^{\circ}, 0^{\circ}\right]$ lay-up). The core is made of Rohacell, $200 \mu \mathrm{m}$ thick carbon skin and 50 $\mu \mathrm{m}$ thick Kapton. The data points refer to the different locations of the dial indicator stylus. The geometrical differences between the shells are likely to cause the sag discrepancy between the two sides of the stave. Problems with the glue seam between the shells can probably explain the poor performance of this stave. 
Stave \#5 Deflection - $\left[0^{\circ} / \pm^{\circ} 45 / 0^{\circ} / \pm 45^{\circ} / 0^{\circ}\right]$

dogbones glued on flanges only - stave weight $=67.10 \mathrm{gr} /$ glue: DP-190

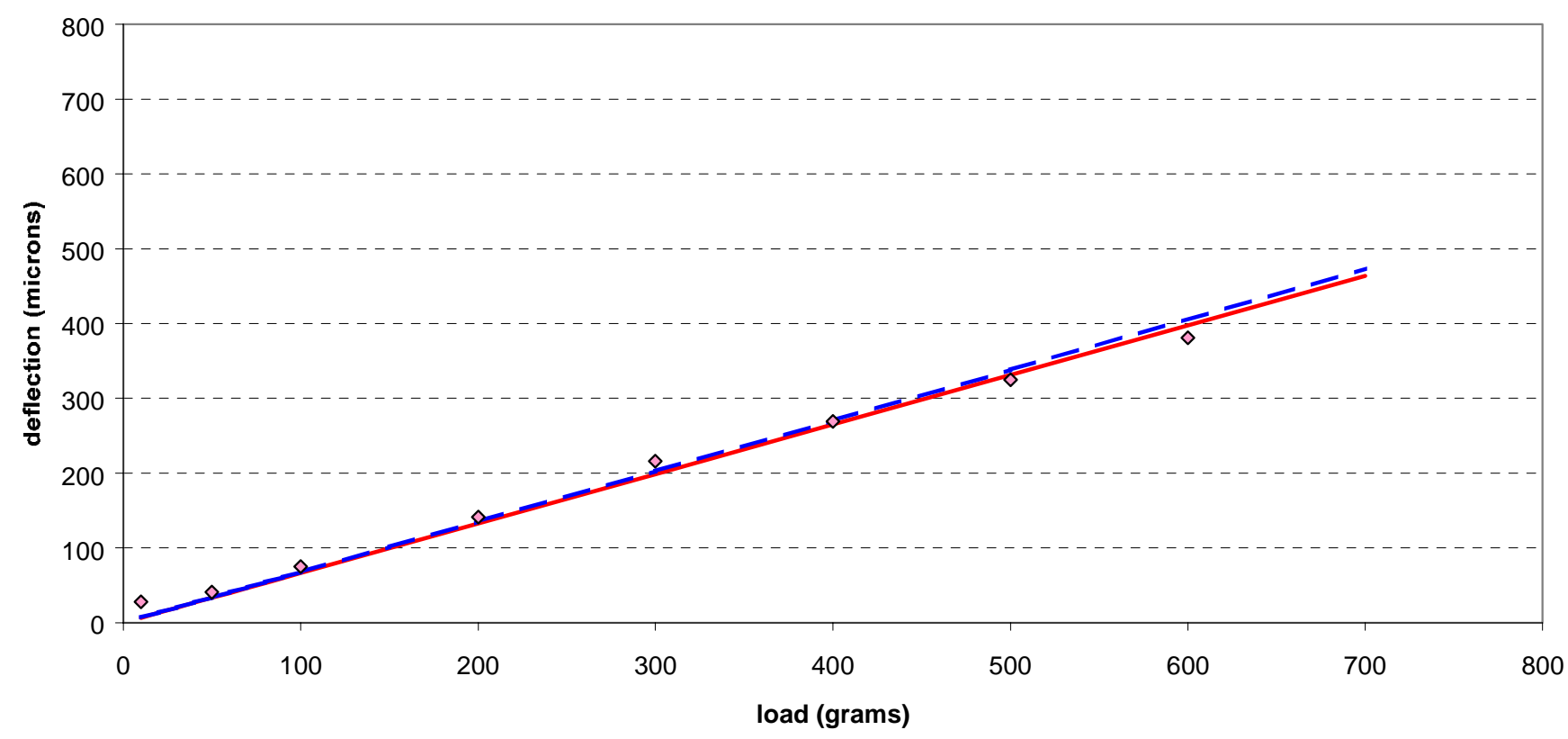

$\diamond \quad$ C CHANNEL \#5 — theor. prediction $[0 \pm 450 \pm 450]-$ Design Goal

Figure 12 - Stave \#5 mockup deflection study. The only structural difference between this model and stave \#3 is in the C channel fiber lay-up (Mitsubishi K139 [0 / \pm 45$]$ ). This contributes slightly to the bending stiffness of the structure, although the lesser stave overall height $(\sim 8.71 \mathrm{~mm}$ vs the $9.20 \mathrm{~mm})$ counteracts this. The core is made of Rohacell and 6 mils thick Kevlar. 
Stave \#6 Deflection - $\left[0^{\circ} / \pm^{\circ} 45 / 0^{\circ} / \pm 45^{\circ} / 0^{\circ}\right]$

dogbones glued on flanges only - stave weight $=61.81 \mathrm{gr} /$ glue: DP-190

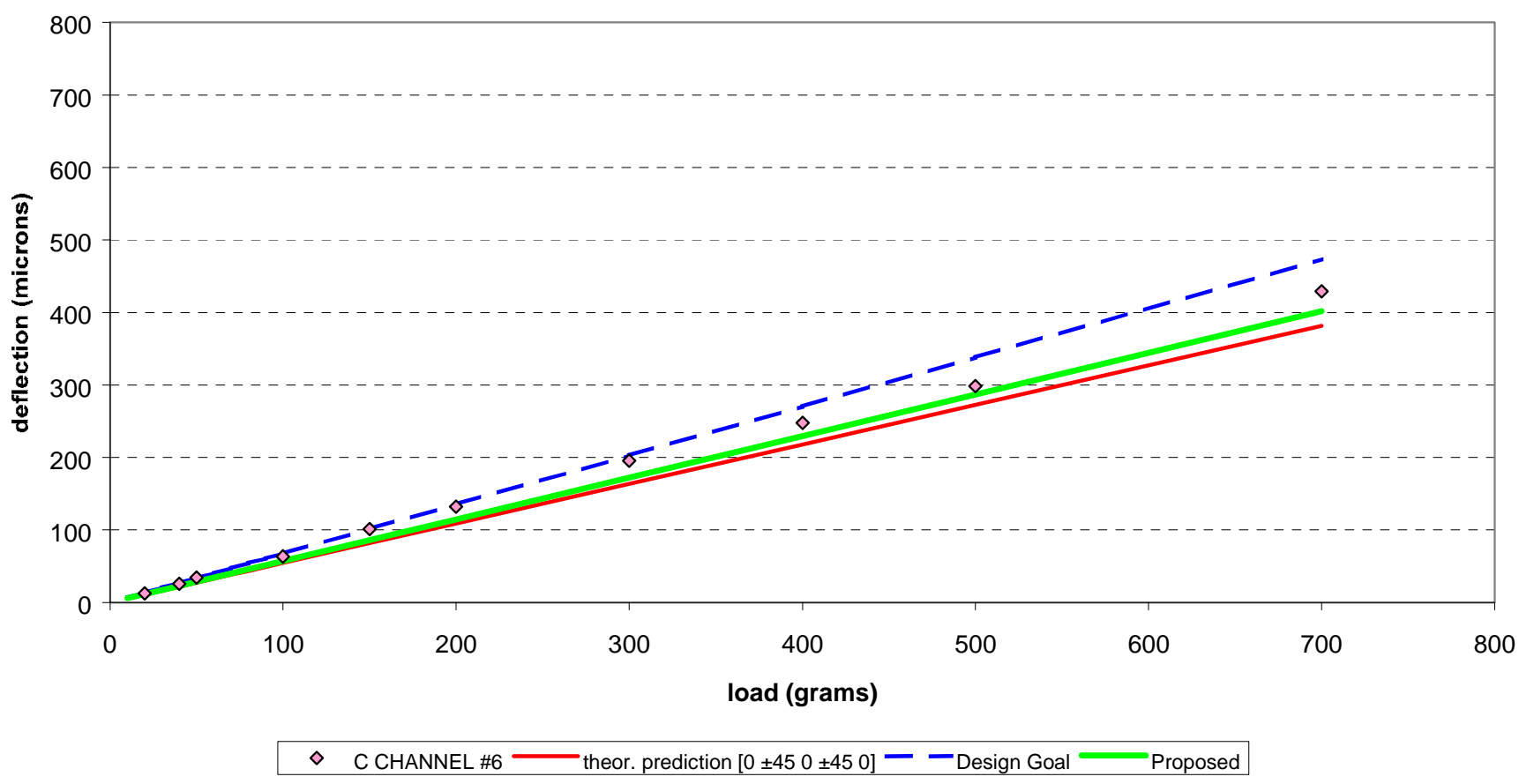

Figure 13 - Stave \#6 mockup deflection study. Similar to stave \#5 but with fiberglass skin core about 3 mils thick. The green line shows how the channel structure with the proposed lay-up is expected to perform.

The figure of merit $(F M)$ reported in the last column of Table 2 provides a quick way to compare the different mockups analyzed so far. It is calculated using the following relation

$$
F M=\frac{60 \mu m}{\text { calculated_sag }_{\text {sal }}} \times \frac{(8.8 \mathrm{~mm}-\text { goal_wall_thickness })^{2}}{(\text { measured_mockup_height }- \text { measured_wall_thickness })^{2}}
$$

Equation 2

$60 \mu \mathrm{m}$ being the goal maximum sag, $8.8 \mathrm{~mm}$ the overall stave height, and the goal wall thickness is $250 \mu \mathrm{m}$ for the shell design and $360 \mu \mathrm{m}$ for the channel configuration. Since according to Equation 2 values of $F M$ greater than 1 indicate a design performing better than our goal, it follows that only the channel solution is capable of meeting the specified requirements of stiffness, with stave \#6 being the best performer. 


\section{Channel development}

The actual channel can be further improved adopting a thinner ply with a less resin rich prepreg. This has the double advantage to increase the laminate bending stiffness and reduce the wall thickness (allowing extra safe space for the wirebonds).

Table 1 shows the properties of a laminate made with a K139/EX1515 lamina (Mitsubishi K139 fiber $55 \mathrm{gsm}$ fiber areal weight, $45 \mu \mathrm{m}$ ply thickness - with $29.3 \%$ by mass EX1515 resin $^{7}$ ) and the following 8 plies lay-up: $\left[0^{\circ}, \pm 45^{\circ}, 0^{\circ}, 0^{\circ}, \pm 45^{\circ}, 0^{\circ}\right]$.

\begin{tabular}{|c|c|c|c|}
\hline Ex (pa) & $2.21 \mathrm{E}+11$ & Ex (psi) & $3.20 \mathrm{E}+07$ \\
\hline Ey (pa) & $4.87 \mathrm{E}+10$ & Ey (psi) & $7.06 \mathrm{E}+06$ \\
\hline $\mathrm{Ez}(\mathrm{pa})$ & $6.30 \mathrm{E}+09$ & $\mathrm{Ez}$ (psi) & $9.13 \mathrm{E}+05$ \\
\hline Gxy (pa) & $5.54 \mathrm{E}+10$ & Gxy (psi) & $8.03 E+06$ \\
\hline Gxz (pa) & $3.93 \mathrm{E}+09$ & Gxz (psi) & $5.69 \mathrm{E}+05$ \\
\hline Gyz (pa) & $2.98 \mathrm{E}+09$ & Gyz (psi) & $4.33 \mathrm{E}+05$ \\
\hline NUxy & $8.84 \mathrm{E}-01$ & NUxy & $8.84 \mathrm{E}-01$ \\
\hline NUyx & $1.95 \mathrm{E}-01$ & NUyx & 1.95E-01 \\
\hline NUxz & $7.89 \mathrm{E}-03$ & NUxz & 7.89E-03 \\
\hline NUzx & $2.25 \mathrm{E}-04$ & NUzX & 2.25E-04 \\
\hline NUyz & $2.07 \mathrm{E}-01$ & NUyz & 2.07E-01 \\
\hline NUzy & $2.67 \mathrm{E}-02$ & NUzy & 2.67E-02 \\
\hline CTEX & $-1.42 \mathrm{E}-06$ & CTEx (in/in/F) & $-7.90 \mathrm{E}-07$ \\
\hline CTEy & $1.50 \mathrm{E}-06$ & CTEy (in/in/F) & $8.32 \mathrm{E}-07$ \\
\hline CTEz & $3.67 \mathrm{E}-05$ & CTEz (in/in/F) & 2.04E-05 \\
\hline CTEyz & $0.00 \mathrm{E}+00$ & CTEyz (in/in/F) & $0.00 \mathrm{E}+00$ \\
\hline CTEzx & $0.00 \mathrm{E}+00$ & CTEzx (in/in/F) & $0.00 \mathrm{E}+00$ \\
\hline CTExy & $-4.49 \mathrm{E}-22$ & CTExy (in/in/F) & $0.00 \mathrm{E}+00$ \\
\hline CMEx & $-2.34 \mathrm{E}-05$ & CMEx & $-2.34 \mathrm{E}-05$ \\
\hline CMEy & $1.85 \mathrm{E}-03$ & CMEy & $1.85 \mathrm{E}-03$ \\
\hline $\mathrm{CMEz}$ & $2.44 \mathrm{E}-02$ & $\mathrm{CMEz}$ & 2.44E-02 \\
\hline CMEyz & $0.00 \mathrm{E}+00$ & CMEyz & $0.00 \mathrm{E}+00$ \\
\hline CMEzx & $0.00 \mathrm{E}+00$ & CMEzx & $0.00 \mathrm{E}+00$ \\
\hline CMExy & $-2.80 \mathrm{E}-19$ & CMExy & $0.00 \mathrm{E}+00$ \\
\hline $\mathrm{Kx}(\mathrm{W} / \mathrm{m} / \mathrm{K})$ & $8.95 \mathrm{E}+01$ & $\mathrm{Kx}(\mathrm{Btu} / \mathrm{hr} / \mathrm{ft} / \mathrm{F})$ & $5.17 \mathrm{E}+01$ \\
\hline $\mathrm{Ky}(\mathrm{W} / \mathrm{m} / \mathrm{K})$ & $3.01 \mathrm{E}+01$ & $\mathrm{Ky}(\mathrm{Btu} / \mathrm{hr} / \mathrm{ft} / \mathrm{F})$ & $1.74 \mathrm{E}+01$ \\
\hline $\mathrm{Kz}(\mathrm{W} / \mathrm{m} / \mathrm{K})$ & 3.23E-01 & $\mathrm{Kz}(\mathrm{Btu} / \mathrm{hr} / \mathrm{ft} / \mathrm{F})$ & 1.87E-01 \\
\hline $\mathrm{Kxy}(\mathrm{W} / \mathrm{m} / \mathrm{K})$ & $5.85 \mathrm{E}-16$ & Kxy & $-1.26 \mathrm{E}-17$ \\
\hline $\operatorname{Den}(\mathrm{g} / \mathrm{m} 3)$ & $1.73 \mathrm{E}+06$ & Den (lb/in3) & $6.24 \mathrm{E}-02$ \\
\hline Thick (mm) & $3.60 \mathrm{E}-01$ & Thick (in) & 1.42E-02 \\
\hline
\end{tabular}

Table 1 - Laminate properties for K139 fiber with $30 \%$ mass $R S-12$ polycyanate resin and $\left[0^{\circ} / \pm 45^{\circ} / 0^{\circ} / 0^{\circ} / \pm 45^{\circ} / 0^{\circ}\right]$ lay-up.

${ }^{7} \mathrm{EX} 1515$ is a $225-250^{\circ} \mathrm{F}$ cure toughened cyanate resin for spacecraft and other cryogenic applications that require temperature stable structures. 
The use of such a laminate to build a $8.8 \mathrm{~mm}$ high $\times 14.5 \mathrm{~mm}$ wide channel would give a predicted bending moment of $120 \mathrm{~m}^{4} \times \mathrm{Pa}$, which is a $76 \%$ gain from the design goal. This yields $34 \mu \mathrm{m}$ sag under the $0.013 \mathrm{lbf} / \mathrm{in}$ load and a $109 \mathrm{~Hz}$ fundamental frequency for the structure. In this case the figure of merit would be 1.76 .

\begin{tabular}{|c|c|c|c|c|c|c|c|c|c|}
\hline $\begin{array}{c}\text { Stave } \\
\#\end{array}$ & Design & $\begin{array}{c}\text { shell / } \\
\text { channel } \\
w[\mathrm{~mm}] \times \\
h[\mathrm{~mm}]\end{array}$ & lay-up & $\begin{array}{c}\text { lay-up } \\
\text { thckns } \\
{[\mu \mathrm{m}]}\end{array}$ & $\begin{array}{c}\text { stave } \\
\text { mass } \\
{[g r]}\end{array}$ & $\underset{\left[m^{4} \times P a\right]}{\boldsymbol{E I}}$ & $\begin{array}{c}\text { sag@ } \\
0.013 l b \\
\text { /in } \\
{[\mu m]}\end{array}$ & $\underset{[H z]}{\boldsymbol{f}}$ & $F M$ \\
\hline $\mathbf{0}$ & $\begin{array}{c}\text { shell } \\
\text { [ small cut-outs] } \\
\text { ! TOO TALL! }\end{array}$ & $47.2 \times 10.0$ & $\begin{array}{c}0^{\circ} / 0^{\circ} / 90^{\circ} \\
/ 0^{\circ} / 0^{\circ}\end{array}$ & 300 & 72.42 & 77 & 53 & 87 & 0.88 \\
\hline 1 & $\begin{array}{c}\text { C channel } \\
\text { [ } 15 \mathrm{~mm} \text { wide dog- } \\
\text { bones glued on } \mathrm{Si}]\end{array}$ & $13.2 \times 8.9$ & $\begin{array}{c}0^{\circ} / \pm 45^{\circ} / \\
\mathrm{Al} / \pm 45^{\circ} / \\
0^{\circ}\end{array}$ & 350 & 77.60 & 41 & 101 & 63 & 0.60 \\
\hline 2 & $\begin{array}{c}\text { C channel } \\
\text { [ 7.5mm wide dog- } \\
\text { bones glued on } \mathrm{Si} \text { ] }\end{array}$ & $15.6 \times 9.1$ & $\begin{array}{l}0^{\circ} * / \pm 60^{\circ} \\
/ 0^{\circ} / \pm 60^{\circ} / \\
0^{\circ} *\end{array}$ & 480 & 72.79 & 84 & 49 & 91 & 1.23 \\
\hline 3 & $\begin{array}{c}\text { C channel } \\
\text { [ 7.5mm wide dog- } \\
\text { bones NOT on } \mathrm{Si} \text { ] }\end{array}$ & $15.4 \times 9.2$ & $\begin{array}{c}0^{\circ} * / \pm 60^{\circ} \\
/ 0^{\circ} / \pm 60^{\circ} / \\
0^{\circ} *\end{array}$ & 410 & 64.77 & 74 & 56 & 85 & 1.08 \\
\hline 4 & $\begin{array}{c}\text { shell } \\
\text { [ final cut-outs } \\
\text { layout ] }\end{array}$ & $46.7 \times 8.75$ & $\begin{array}{c}0^{\circ} / \pm 60^{\circ} / \\
\pm 60^{\circ} / 0^{\circ}\end{array}$ & 250 & 65.86 & 25 & 162 & 50 & 0.37 \\
\hline 5 & $\begin{array}{c}\text { C channel } \\
\text { [ 7.5mm wide dog- } \\
\text { bones NOT on } \mathrm{Si}- \\
\text { Kevlar skin core ] }\end{array}$ & $\begin{array}{r}15.5 \times \\
8.72^{8}\end{array}$ & $\begin{array}{c}0^{\circ} / \pm 45^{\circ} / \\
0^{\circ} / \pm 45^{\circ} / \\
0^{\circ}\end{array}$ & $420^{8}$ & 67.10 & 70 & 59 & 83 & 1.02 \\
\hline 6 & $\begin{array}{c}\mathrm{C} \text { channel } \\
\text { [ } 7.5 \mathrm{~mm} \text { wide dog- } \\
\text { bones NOT on } \mathrm{Si}- \\
\text { Fiberglass skin } \\
\end{array}$ & $\begin{array}{c}15.35 \times \\
9.13^{8}\end{array}$ & $\begin{array}{c}0^{\circ} / \pm 45^{\circ} / \\
0^{\circ} / \pm 45^{\circ} / \\
0^{\circ}\end{array}$ & $476^{8}$ & 61.81 & 85 & 48 & 92 & 1.24 \\
\hline$*$ & $\begin{array}{c}\text { Proposed } \\
\text { prepreg lay-up } \\
\text { C channel }\end{array}$ & $14.5 \times 8.8$ & $\begin{array}{c}0^{\circ} / \pm 45^{\circ} / \\
0^{\circ} / 0^{\circ} / \\
\pm 45^{\circ} / 0^{\circ}\end{array}$ & 360 & 45.8 & 81 & 51 & 89 & 1.18 \\
\hline
\end{tabular}

Table 2 - Summary of the stave mockups characteristics: stave design, dimensions of the adopted structural solution, prepreg lay-up, stave mass, bending stiffness, estimated sag for the expected distributed load, stave fundamental frequency, figure of merit. The figure of merit (FM) reported in the last column provides a quick way to compare the different mockups analyzed so far (the higher the better; a design with FM less than 1 does not meet the specified requirements of stiffness).

${ }^{8} \mathrm{CMM}$ measurement. 
Fermi National Accelerator Laboratory

Giobatta Lanfranco Silicon Engineering Group - Mechanical Dep.

\section{References}

1. «Roark's Formulas for stress and strain», W.C. Young, R.G. Budynas, $7^{\text {th }}$ ed., McGraw Hill 